\title{
A composition-independent quantitative determination of the water content in silicate glasses and silicate melt inclusions by confocal Raman spectroscopy
}

\author{
Journal Article \\ Author(s): \\ W.; Morizet, Yann; Müntener, Othmar; Ulmer, Peter; Webster, James D. \\ Publication date: \\ 2005-12 \\ Permanent link: \\ https://doi.org/10.3929/ethz-b-000030720 \\ Rights / license: \\ In Copyright - Non-Commercial Use Permitted \\ Originally published in: \\ Contributions to Mineralogy and Petrology 150(6), https://doi.org/10.1007/s00410-005-0040-9
}

Zajacz, Zoltán; Halter, Werner; Malfait, Wim J.; Bachmann, Olivier; Bodnar, Robert J.; Hirschmann, Marc M.; Mandeville, Charles 
ORIGINAL PAPER

Zoltán Zajacz • Werner Halter · Wim J. Malfait

Olivier Bachmann • Robert J. Bodnar

Marc M. Hirschmann - Charles W. Mandeville

Yann Morizet · Othmar Müntener · Peter Ulmer

James D. Webster

\section{A composition-independent quantitative determination of the water content in silicate glasses and silicate melt inclusions by confocal Raman spectroscopy}

Received: 16 May 2005/ Accepted: 1 September 2005/Published online: 8 November 2005

(C) Springer-Verlag 2005

Abstract A new approach was developed to measure the water content of silicate glasses using Raman spectroscopy, which is independent of the glass matrix composition and structure. Contrary to previous studies, the

Communicated by T.L. Grove

Z. Zajacz $(\bowtie) \cdot$ W. Halter · W. J. Malfait · Y. Morizet Department of Earth Sciences, Isotope Geochemistry and Mineral Resources, ETH Zürich, 8092, Zürich, Switzerland

E-mail: zajacz@erdw.ethz.ch

Tel.: + 41-1-6320734

Fax: + 41-1-6321827

O. Bachmann

Section des Sciences de la Terre, Université de Genève,

Département de Minéralogie 13, rue des Maraichers,

1211, GENEVE 4, Switzerland

R. J. Bodnar

Department of Geosciences, 4044 Derring Hall, Virginia Tech, Blacksburg, VA 24061-0420, USA

M. M. Hirschmann

Department of Geology and Geophysics, University of Minnesota, Minneapolis, MN 55455, USA

C. W. Mandeville $\cdot$ J. D. Webster

Department of Earth and Planetary Sciences, A.M.N.H.

Central Park West at 79th Street, New York,

NY 10024-5192, USA

\section{Y. Morizet}

Now at: Laboratory of Planetology and Geodynamic, University of Nantes, 2 rue de la Houssiniere, 44300, Nantes, France

O. Müntener

Institute of Geological Sciences, University of Bern,

Baltzerstr. 1, 3012, Bern, Switzerland

P. Ulmer

Department of Earth Sciences,

Institute for Mineralogy and Petrology, ETH Zürich,

8092, Zürich, Switzerland compositional range of our studied silicate glasses was not restricted to rhyolites, but included andesitic, basaltic and phonolitic glasses. We used 21 glasses with known water contents for calibration. To reduce the uncertainties caused by the baseline removal and correct for the influence of the glass composition on the spectra, we developed the following strategy: (1) application of a frequency-dependent intensity correction of the Raman spectra; (2) normalization of the water peak using the broad $\mathrm{T}-\mathrm{O}$ and $\mathrm{T}-\mathrm{O}-\mathrm{T}$ vibration band at 850 $1250 \mathrm{~cm}^{-1}$ wavenumbers (instead of the low wavenumber $\mathrm{T}-\mathrm{O}-\mathrm{T}$ broad band, which appeared to be highly sensitive to the $\mathrm{FeO}$ content and the degree of polymerization of the melt); (3) normalization of the integrated $\mathrm{Si}-\mathrm{O}$ band area by the total number of tetrahedral cations and the position of the band maximum. The calibration line shows a $\pm 0.4 \mathrm{wt} \%$ uncertainty at one relative standard deviation in the range of $0.8-9.5 \mathrm{wt} \%$ water and a wide range of natural melt compositions. This method provides a simple, quick, broadly available and cost-effective way for a quantitative determination of the water content of silicate glasses. Application to silicate melt inclusions yielded data in good agreement with SIMS data.

\section{Introduction}

The water content of silicate magmas has a dramatic effect on most physicochemical properties, such as liquidus and solidus temperatures, phase assemblages during crystallization or the viscosity of the silicate liquid. Timing of volatile saturation has a major influence on the formation of magmatic-hydrothermal ore deposits and exerts prime control on a variety of volcanic processes. Melt inclusions provide a unique opportunity to reconstruct the changes in the melt 
composition of magmatic systems during their evolution. In particular, quantitative determination of the dissolved water content of melt inclusions provides essential information for the understanding of magmatic processes.

Three different in-situ analytical techniques are commonly applied to determine the water contents of melt inclusions, namely SIMS (secondary ion mass spectrometry), EMP (electron microprobe) and FTIR (Fourier-transformed infrared spectroscopy); each having advantages and limitations. SIMS allows a direct determination of the water content, but the minimum inclusion size needed is $15-20 \mu \mathrm{m}$ and calibration of the instrument requires standard glasses with chemical compositions similar to the unknown sample (Ihinger et al. 1994a; Devine et al. 1995; Hauri et al. 2002; King et al. 2002). In addition, measurement of water-rich glasses is difficult because of the mobility of molecular water in glasses under ion bombardment (Ihinger et al. 1994a; Devine et al. 1995; Morgan and London 1996; Hauri et al. 2002). Alternatively, the water content might be determined indirectly from EMP analysis by the difference between the total of the actual measurement and $100 \%$. However, the presence of other volatiles, the mobility of alkaline elements during the analysis or the various oxidation states of $\mathrm{Fe}$ may introduce large uncertainties (Devine et al. 1995; Morgan and London 1996). A more accurate way to constrain the water content with EMP analysis is to directly measure the oxygen content of the glass and assign the excess oxygen to water (Nash 1992; Devine et al. 1995; Gaetani and Grove 1998; Muntener et al. 2001). Infrared spectroscopy requires melt inclusions of at least $25-35 \mu \mathrm{m}$ in diameter as well as samples that are polished on both sides (Devine et al. 1995; Lowenstern 1995; King et al. 2002). A pre-requisite for all these methods is that the melt inclusions are exposed to the section surface, which is time consuming and allows interaction with air.

Recently, two studies have shown that Raman spectroscopy can be applicable for routine analysis of the water content in silicate glasses (Thomas 2000; Chabiron et al. 2004). This method has the advantage of allowing analyses of small (down to $5 \mu \mathrm{m}$ ) and unexposed melt inclusions, of a broad availability and a short analytical time. However, the glasses used for the calibration in these studies were all rhyolitic in composition with nearly completely polymerized structures and $\mathrm{NBO} / \mathrm{T}$ (number of non-bridging oxygen atoms divided by the number of tetrahedral sites) close to 0 . The area of the water band in the Raman spectra was normalized to the area of the wide band centered at $480 \mathrm{~cm}^{-1}$, which is assigned to asymmetric stretching vibration of $\mathrm{T}-\mathrm{O}-\mathrm{T}$ linkages. These studies describe a good linear correlation between the normalized area of the water peak and the total water content of their samples. However, the effect of the chemical composition of the glass on this $\mathrm{T}-\mathrm{O}-\mathrm{T}$ peak has not been evaluated.
The application of this approach to glasses was tested with intermediate to mafic compositions and several difficulties were encountered due to inconsistent baseline removal and a strong effect of the glass composition on the size of the T-O-T band. To overcome these difficulties, a new quantification procedure was developed to determine the water content of silicate glasses with Raman spectroscopy that is appropriate for a wide compositional range, encompassing rhyolitic to basaltic compositions. A new routine is provided for spectral treatment and water peak area normalization, based on the normalization with the broad Raman band between 850 and $1,250 \mathrm{~cm}^{-1}$.

\section{Approach}

The integrated area of the water band is considered to represent the total water content of the glass. However several instrumental and analytical parameters can influence its size, such as the size of the confocal volume, the reflectance at the sample surface or absorption in the excited volume. Quantification of the water content thus, requires normalization of the water band by an internal standard. In this study the area of the broad Raman band between 850 and $1,250 \mathrm{~cm}^{-1}$ Raman shift was used to normalize the integrated area of the water peak. Since this band is overlapping with unidentified spectral components at low wavenumbers, deconvolution of the spectra is required to get the proper area of the band in various glasses. Since the area of the Raman band used for normalization is not composition-independent a correction method was developed to compensate for the effect of the glass composition. The normalized water peak area can be calibrated using samples with known water contents.

\section{Characteristics of the $850-1250 \mathrm{~cm}^{-1}$ Raman band}

In the low wavenumber region of the silicate glass spectra, two major Raman bands are present: one is centered on $480 \mathrm{~cm}^{-1}$ and another around $1,050 \mathrm{~cm}^{-1}$. Both bands are the sum of several Raman bands corresponding to different bridging and non-bridging $\mathrm{T}-\mathrm{O}$ vibrations in the glass structure. The band at $480 \mathrm{~cm}^{-1}$ is assigned to Raman scattering of $\mathrm{T}-\mathrm{O}-\mathrm{T}$ linkages of four- and six-membered silica tetrahedra rings of the glass network (Matson et al. 1983; Sharma et al. 1997). Assignment of the wide band between 850 and $1,250 \mathrm{~cm}^{-1}$ is difficult in systems having several components such as natural melts. However, there are abundant data on three component systems that allow interpretation of this band. In alkalifeldspathic systems, with completely polymerized structures $(\mathrm{NBO} / \mathrm{T}=0)$ Raman scattering occurs on two major asymmetric stretching vibrations of $\mathrm{T}-\mathrm{O}-\mathrm{T}$ linkages. This generates appearance of two Raman bands: one located at 
$1,105 \mathrm{~cm}^{-1}$ and another located at $1,020 \mathrm{~cm}^{-1}$. The origin of this doublet is still unclear (McMillan et al. 1982; Sharma et al. 1997).

In depolymerized systems, new Raman bands appear in the region between 850 and $1,150 \mathrm{~cm}^{-1}$, which are assigned to $\mathrm{T}-\mathrm{O}$ stretching modes of different structural species in the glass. The most intense band centered at $1,080-1,100 \mathrm{~cm}^{-1}$ is generally considered as the $\mathrm{T}-\mathrm{O}$ stretching mode of $\mathrm{Q}^{3}$ species (structural units with three bridging oxygens; McMillan et al. 1982; Wang et al. 1993; Mysen 1997, 1999). Other bands at higher and lower wavenumbers are also present and tentatively assigned to a $\mathrm{Q}^{3}$ species connected to a $\mathrm{Q}^{4}$ species and a $\mathrm{Q}^{2}$ species, respectively (McMillan et al. 1992), however the assignment of these latter peaks is still under debate (McMillan et al. 1992; Mysen 1999). The presence of Fe in both polymerized and depolymerized systems generates a new band centered around $940-970 \mathrm{~cm}^{-1}$, which is assigned to Fe-O-Si linkages (Wang et al. 1993; Wang et al. 1995; Sharma et al. 1997).

The exact position and the relative intensity of all these bands is a function of the glass composition, but they are always located within the $850-1250 \mathrm{~cm}^{-1}$ wavenumber region (McMillan et al. 1982; Wang et al. 1993; Mysen 1997, 1999).

\section{Analytical techniques}

All measurements were carried out with a Dilor LabRam II confocal Raman microspectrometer at ETH Zürich. An Olympus microscope is attached to the LabRam II and a 50× objective was used for all analyses. A 488-nm Ar + laser (Inova 90) was used to excite the sample. The applied laser output energy was $600 \pm 3 \mathrm{~mJ}$. The instrument is equipped with a beam splitter to protect the notch filter from the high-energy laser irradiation. The beam splitter reflects $30 \%$ of the incident laser energy (output energy) to the sample and allows $70 \%$ of the scattered light to reach the detector after passing through a notch filter. The energy of the incident laser light on the sample surface was $180 \mathrm{~mJ}$.

A $60 \mathrm{~s}$ acquisition time was used for glasses with water contents above $3 \mathrm{wt} \%$, glasses with lower water content were measured over $180 \mathrm{~s}$ to improve the signal to noise ratio. Acquisitions were repeated at least three times.

The confocal device allows analysis of a laterally and vertically limited volume of sample at the sample surface or within the sample. The size of this volume can be regulated by varying the size of the confocal pinhole. Vertical and horizontal dimensions of the confocal volume were tested before the measurement. To check the horizontal position and extension the laser diode built in the instrument was used. To check the vertical dimension, the change in signal intensity was measured from a reflecting surface (Si-plate) by focusing at various distances from the surface. This was necessary because the vertical dimension of the confocal volume is not well defined and can be several times the lateral dimension. A Raman-inactive metal plate was placed under all thin glass samples (thickness $<50 \mu \mathrm{m}$ ) to avoid any interference with the sample holder.

Possible water loss induced by sample heating through the absorbed laser light during the analysis was tested by repeated measurements of the same spot in various glasses. Results show that the area of the water peak did not change over a 20 -min irradiation time. Furthermore, the laser was focused $20 \mu \mathrm{m}$ beneath the sample surface for measurements in glasses. The dependence of the calculated peak area ratio on the focus position from 0 to $30-\mu \mathrm{m}$ depth was also tested. Results scattered over 3\% relative but without any systematic shift. However, the signal to noise ratio was much better when focusing beneath the surface, since the entire confocal volume was inside the sample. For measurements in experimental glasses, a relatively large confocal hole size of $1,200 \mu \mathrm{m}$ was used in order to sample a larger volume and get spectra of higher quality. With this hole size, the horizontal dimension of the confocal volume is $17 \mu \mathrm{m} ; 75 \%$ of the signal intensity is coming from a depth interval of $40 \mu \mathrm{m}$. For melt inclusion analyses, the size of the confocal hole was set to sample a volume smaller than the size of the melt inclusion to avoid a contribution from the host mineral. For melt inclusions smaller than $30 \mu \mathrm{m}$ in diameter, a confocal hole size of $300 \mu \mathrm{m}$ or less is generally required. A grating of 1,800 was applied to get high spectral resolution, thus, the spectra of the low- and high-wavenumber regions were acquired separately, right after each other and without moving the sample.

Ion microprobe analyses (SIMS) of melt inclusions trapped in Kos Plateau Tuff crystals were obtained on a Cameca IMS 3f instrument at the Arizona State University. Analytical conditions followed those described by Ihinger et al. (1994b) and Hervig and Dunbar (1992). The accuracy of water determinations were checked by measuring $\mathrm{H}$ in glass standards analyzed by Karl Fischer Titration (Westrich 1987) and errors were estimated to be approximately $0.5 \mathrm{wt} \% \mathrm{H}_{2} \mathrm{O}$. Analytical techniques used for all the experimental glasses and melt inclusions from the Ascension-Island are described in the references cited in Table 1.

\section{Glasses used for calibration}

Since no appropriate water-bearing standard glasses are available for calibration, experimental glasses were used for which the water contents were determined by various analytical techniques. The chemical composition of the glasses, the pressure and the temperature conditions at which they were synthesized, as well as the various techniques by which the water contents were determined are summarized in Table 1.

The compositional range of the glasses used for calibration extends from primitive calc-alkaline basaltic to feldspathic compositions with $\mathrm{NBO} / \mathrm{T}$ values ranging 


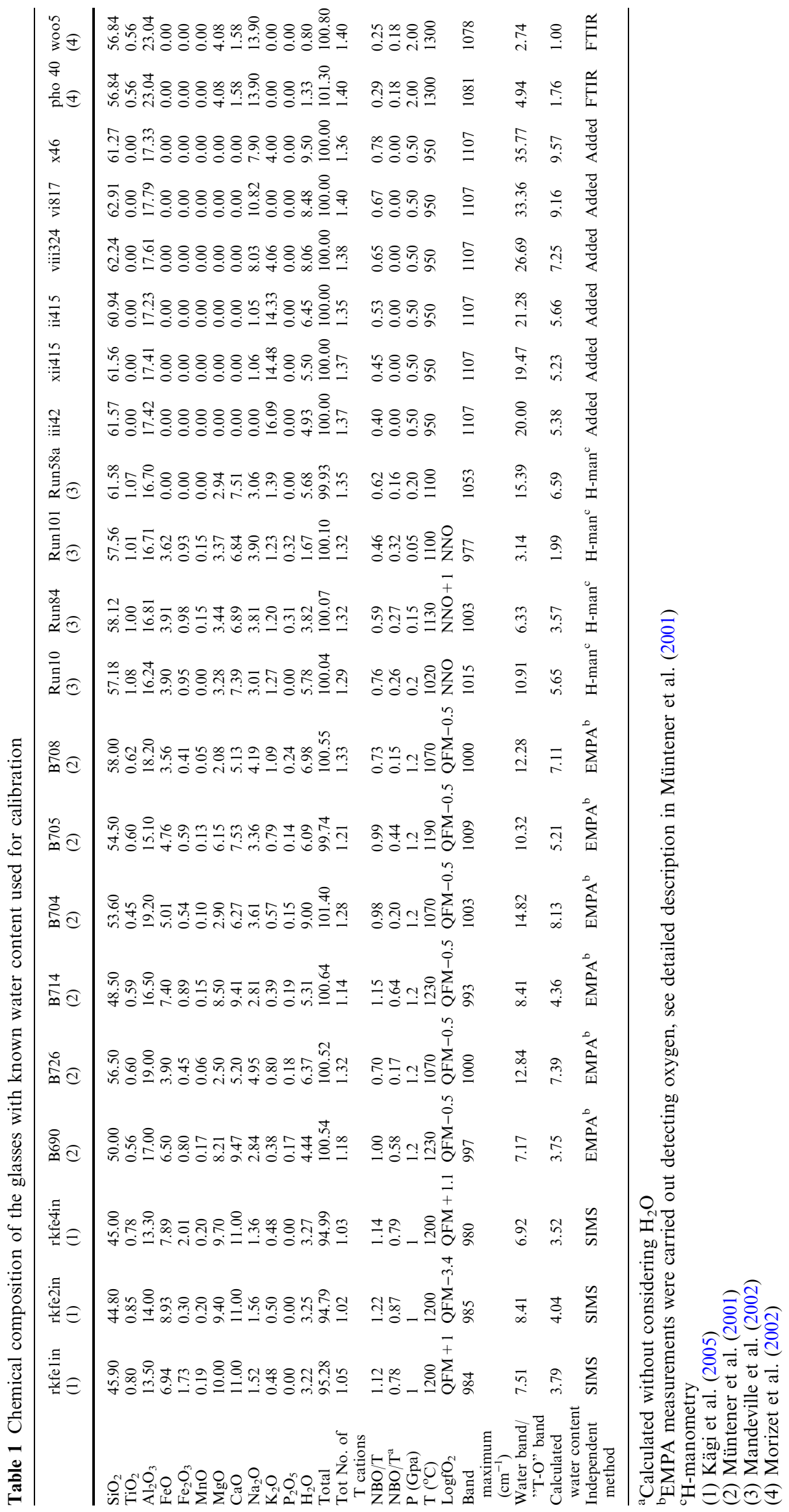


from 0.89 to 0.0 . The total water content varies between 0.8 and $9.5 \mathrm{wt} \%$. The $\mathrm{Fe}(\mathrm{III}) / \mathrm{Fe}(\mathrm{II})$ ratio in each sample was calculated using the method of Kress and Carmichael (1991) based on oxygen-fugacity values of the experiments, which varies significantly between samples (Table 1).

\section{Spectral treatment}

Spectral treatment was carried out using the Origin 7.0 software in three consecutive steps (Fig. 1): (1) baseline removal (2) frequency-temperature correction and (3) deconvolution and band integration.

In most cases, the acquired spectra required baseline removal (step 1) because of the instrumental effects, fluorescence and reflectance of the sample glass under laser irradiation. This background is present in both the regions of the water and the " $\mathrm{T}-\mathrm{O}$ " band. Background removal can be done most consistently through a linear extrapolation of the flat signal from the 1,250 $1,850 \mathrm{~cm}^{-1}$ wave number region towards the broad band between $850-1,250 \mathrm{~cm}^{-1}$ referred as " $\mathrm{T}-\mathrm{O}$ " band later in the text for simplification (Fig. 1). The accuracy with which this extrapolation represents the actual baseline decreases towards low wavenumbers, but for the investigated spectral region $\left(630 \mathrm{~cm}^{-1}-1250 \mathrm{~cm}^{-1}\right)$ this approach provided the best results in terms of reproducibility. This linear extrapolation was exclusively used in this study.

For the water band, removal of a nearly linear and constant baseline was appropriate in most cases (Fig. 1). The band starts between 2,800 and $2,830 \mathrm{~cm}^{-1}$ and ends at $3,775 \pm 10 \mathrm{~cm}^{-1}$. Fitting the baseline for the water band is more reproducible, and results in a lower uncertainty in the peak area than the baseline removal for the " $\mathrm{T}-\mathrm{O}$ " band. However, it is worth mentioning that even small uncertainties in the baseline removal result in significant changes in the deconvolution of the water band as discussed later.

Step 2 consisted of the application of a frequencytemperature intensity correction (McMillan and Wolf 1995; Keresztury 2002; Long 2002). The Raman scattering efficiency (i.e., the signal intensity generated by a specific amount of Raman-active species) is a sharply decreasing function of the Raman shift. Thus, this correction is necessary to obtain spectral intensities that are true representations of the abundance of an excited vibration. This correction removes the high artificial shoulder at the beginning of the spectra, and makes the spectral deconvolution simpler and more accurate (Fig. 1). Since band positions shift with variations in the glass composition this correction is crucial to generate a calibration method applicable to a broad compositional range. The correction formula and the correction factor
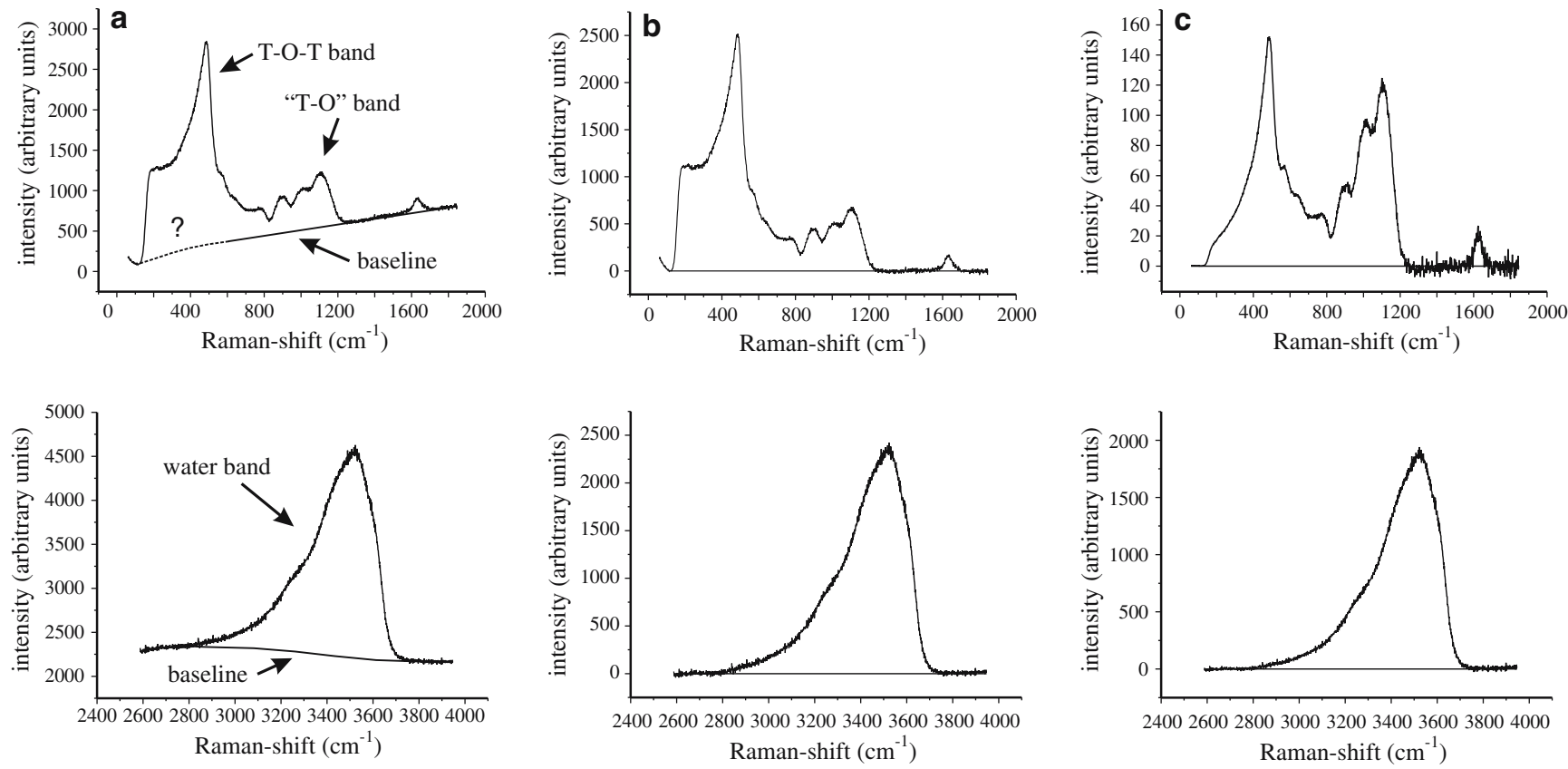

Fig. 1 Spectral treatment process presented on the low wavenumber spectral window that includes all the significant bands of the $\mathrm{T}-\mathrm{O}$ and T-O-T vibrations and on the high wavenumber spectral window with the water band. a the original spectra. In the low wavenumber spectral window the linear part of the spectra at high wavenumbers is extrapolated to the low wavenumber region to get an appropriate and reproducible baseline. The position of the

baseline at the beginning of the spectra is not well defined. In the high wavenumber spectral window usually a nearly linear baseline is appropriate to remove the background of the water band. b baseline-corrected spectra before application of the frequencytemperature correction formula. c spectra after the frequencytemperature correction 


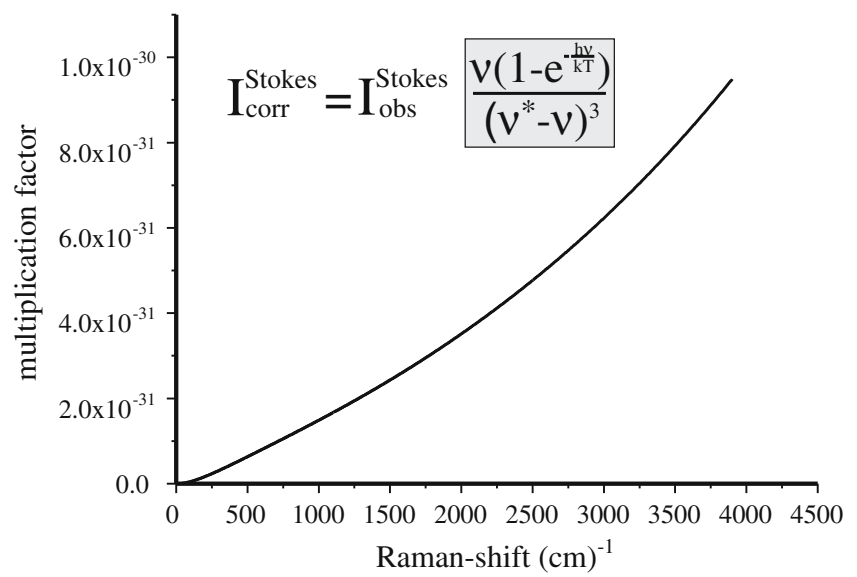

Fig. 2 Effect of the frequency-temperature correction. The curve shows the multiplication factor as a function of the Raman shift $\left(\mathrm{cm}^{-1}\right)$ at room temperature. It is apparent that since the slope of the curve is relatively steep it will result in significant differences in band height and area ratios if the bands are shifted by compositional effects. $v^{*}$ is the frequency of the incident laser light, $v$ is the frequency of the Raman-scattered light, $T$ is the temperature in $\mathrm{K}$ at which the measurement was done

applied for the 488-nm laser light at room temperature (McMillan and Wolf 1995; Long 2002) are shown in Fig. 2 as a function of the Raman shift. The Ramanscattering efficiency is also dependent on the temperature. Thus heating of the sample by the laser might potentially influence the calibration. However, the influence of a $100-\mathrm{K}$ temperature increase was calculated and it caused only $1.6 \mathrm{rel} \%$ difference in the final peak area ratio used for quantification of the water content.

Step 3 of the spectral treatment was the deconvolution of the $630-1,250 \mathrm{~cm}^{-1}$ band region. In general, the use of five Gaussian components in the spectral range between 630 and $1,250 \mathrm{~cm}^{-1}$ is adequate to get reasonably low residuals. Additional peaks do not significantly improve the quality of the fit. The sum of the area of the Gaussian components between 850 and $1,250 \mathrm{~cm}^{-1}$ was used to normalize the area of the water band. Deconvolution of the spectra at wavenumbers below $850 \mathrm{~cm}^{-1}$ by adding additional Gaussian components was only required because these components overlap with those at higher wavenumbers. This overlapping becomes more significant in less polymerized glasses. Typical deconvolutions including the positions of the Gaussian components are shown in Fig. 3 for rhyolitic, andesitic and basaltic glasses, respectively. Note that the position of the Gaussian components is composition-dependent. Three components for rhyolitic and andesitic, four components for basaltic glasses are adequate to properly deconvolute the band. In order to determine accurately the position of the maximum of the "T-O" band a preliminary FFT (fast Fourier transform) smoothing and derivation of the spectra was used. At the band maximum the first derivative is equal to 0 .

It should be emphasized that this procedure for the spectral treatment was designed to be very systematic
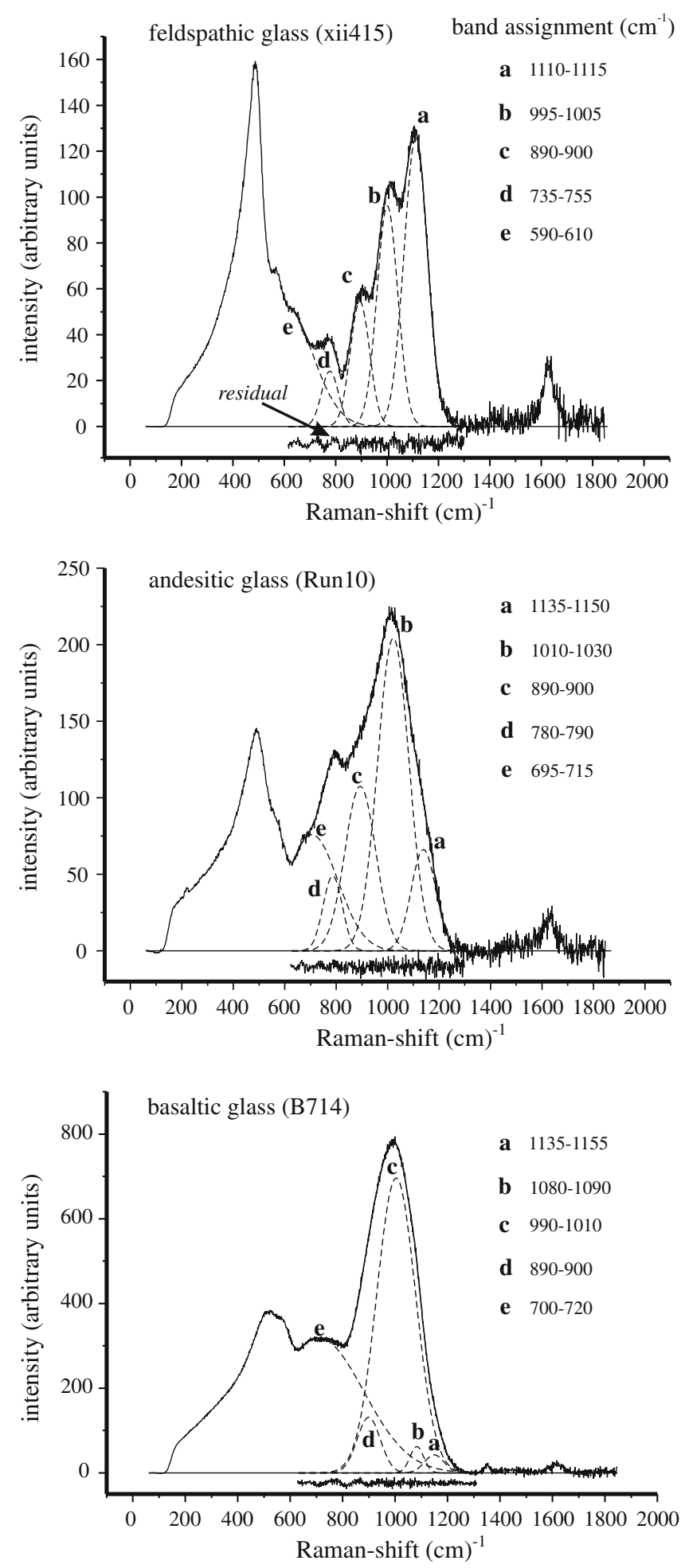

Fig. 3 Typical deconvolution of glasses with different chemical compositions

and leaves little room for interpretation. This is required since small changes in the interpretation of the spectra (e.g., in the evaluation of the baseline) can significantly affect the relative peak areas and the quality of the data. 


\section{Calibration}

Observed compositional effects on the " $\mathrm{T}-\mathrm{O}$ " band

The Raman-spectroscopic observations on the studied glasses representing natural multicomponent systems are in good agreement with the results from synthetic systems summarized earlier. A comparison of glass spectra with a gradual increase in $\mathrm{NBO} / \mathrm{T}$ and $\mathrm{FeO}$ content is shown in Fig. 4. It appears from this figure that the peak position is shifted towards lower wavenumbers with increasing $\mathrm{NBO} / \mathrm{T}$ and $\mathrm{FeO}$ content. The gradual disappearance of the $1,100 \mathrm{~cm}^{-1}$ component is explained by the decrease in the $\mathrm{T}-\mathrm{O}-\mathrm{T}$ band, and the increasing intensity in the $950-1,000 \mathrm{~cm}^{-1}$ region could be partly explained by the addition of $\mathrm{FeO}$ into the system and the possible shift of the $\mathrm{Q}^{3}$ peak. Possible effects of the $\mathrm{Fe}(\mathrm{II}) / \mathrm{Fe}(\mathrm{III})$ ratio have not been investigated yet. The peak assigned to the $\mathrm{Q}^{3}$ species is also reported to be shifted towards lower wavenumbers in depolymerized glasses (McMillan et al. 1982; Wang et al. 1993, 1995), which is in good agreement with the observations.

\section{Calibration procedure}

In this study the sum of the area of the Gaussian components displaying maximum Raman shift between 850 and $1,250 \mathrm{~cm}^{-1}$ was used to normalize the integrated area of the water peak. This band is subject to compositional effects as detailed earlier, and glasses with various compositions depict different correlations between the band area ratio and the water content. In Fig. 5 the distribution of the normalized water peak areas is shown

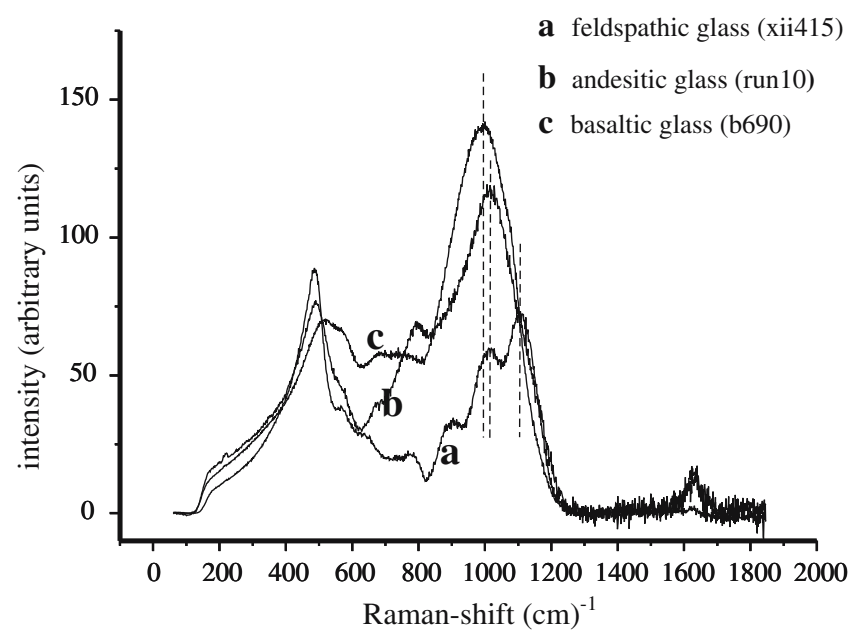

Fig. 4 Comparison of the glass spectra with different chemical composition. The intensities of the spectra are normalized to the water peak area using the known water contents. Intensity growth and shift of the maxima of the "T-O" band are apparent with decreasing $\mathrm{SiO}_{2}$ content. The strong effect of the chemical composition on the T-O-T band centered at $480 \mathrm{~cm}^{-1}$ is also observable especially for mafic compositions
$\Delta$ feldspathic glass serie $(\mathrm{NBO} / \mathrm{T}=0)$

$\nabla$ phonolitic glass serie $(\mathrm{NBO} / \mathrm{T}=0.18)$

- andesitic glass serie $(0.16<\mathrm{NBO} / \mathrm{T}<0.32)$

- basaltic-andesitic, andesitic serie $(0.15<\mathrm{NBO} / \mathrm{T}<0.64)$

$\circ$ basaltic glass serie $(0.78<\mathrm{NBO} / \mathrm{T}<0.87)$

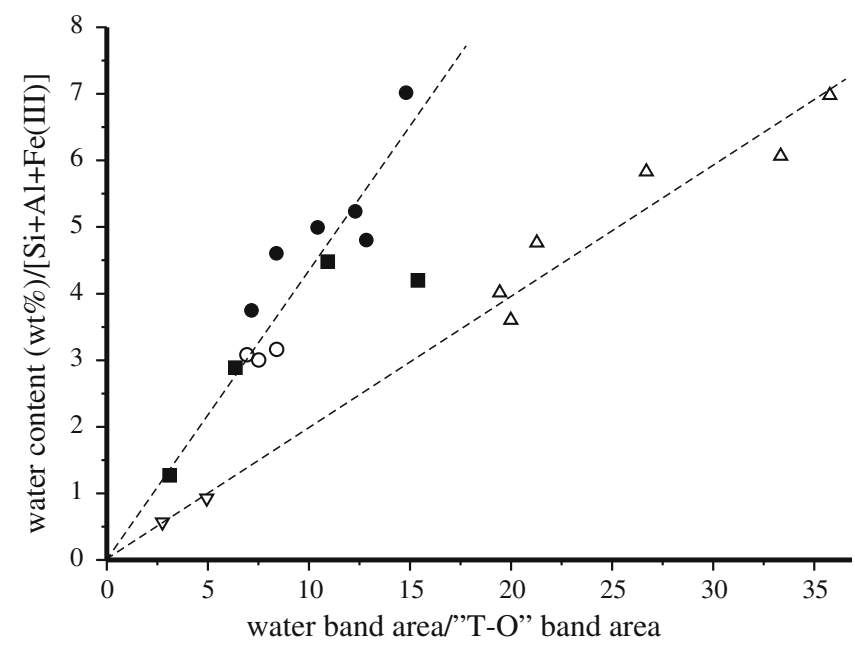

Fig. 5 Primary distribution of the normalized water peak areas as a function of the independently measured water content normalized by the total number of tetrahedral cations. It appears that the feldspathic glasses and basaltic-andesitic and andesitic glasses form separated calibration lines. The basaltic glasses and a synthetic Fefree andesitic glass plot between these lines

as a function of the known total water content normalized by the total number of tetrahedral cations. The data of the basaltic to andesitic and the feldspathic glasses plot on lines that go through the origin but with different slopes. The data of a synthetic Fe-free andesitic glass plots away from both lines.

To remove the compositional effect, a method that compensates for the variation of the " $\mathrm{T}-\mathrm{O}$ " band, based on (1) theoretical and (2) empirical considerations was developed. (1) As detailed earlier, this band results from Raman scattering of different $\mathrm{T}-\mathrm{O}-\mathrm{T}$ and $\mathrm{T}-\mathrm{O}$ species in the glass structure. Since all these species are related to tetrahedral cations, we made a linear correction of the band area with the total number of tetrahedral cations, which can be calculated directly from glass compositions. (2) Since the Raman-scattering efficiency is not the same for the different $\mathrm{T}-\mathrm{O}-\mathrm{T}$ and $\mathrm{T}-\mathrm{O}$ structural species, the band intensity is influenced not only by the absolute abundance but also by the ratio of the different structural species in the glass. Quantification of this effect on a theoretical basis is rather difficult due to insufficient structural information on complex natural compositions. However, most studies conducted on simple ternary silicate systems in the $\mathrm{NBO} / \mathrm{T}$ range characteristic for natural glasses report an absolute intensity growth and a peak shift towards lower wavenumbers with increasing concentration of the network modifier cation. This is in good agreement with the observations on complex glasses. Since no chemical parameter is directly proportional to this speciation, the 
shift in the position of the band maximum was used as a measure of the intensity growth. This empirical correlation can be explained by higher scattering efficiency of species with Raman scattering at lower wavenumbers. The correction formula is based on the shift of the peak maximum relative to the rhyolitic glasses with $\mathrm{NBO} /$ $\mathrm{T}=0$ (i.e., characterized the highest wavenumber for the peak maximum). The equation including the correction factors and the resulting slope of the calibration line is:

$$
\begin{aligned}
\text { Water }_{\text {tot }}= & 0.211 \frac{\text { Water band area }}{\mathrm{T}-\text { O band area }} \\
& \times\left[\frac{1130-(\mathrm{T}-\text { O peak position })}{95}+0.69\right] T_{\mathrm{tot}}
\end{aligned}
$$

where water $r_{\text {tot }}$ is the total water content in wt $\%$, "T-O" band area is the sum of the areas of the Gaussian components of the Raman band between 850 and $1,250 \mathrm{~cm}^{-1}$, "T-O" peak position is the position of the maximum of this band and $T_{\text {tot }}$ is the total number of tetrahedral cations, calculated from electron microprobe data by taking the sum of the atomic abundance of the $\mathrm{Si}^{4+}, \mathrm{Al}^{3+}$ and $\mathrm{Fe}^{3+}$ cations. The atomic abundances were not normalized to any value. The parameters of the correction formula were optimized iteratively to get the best correlation on the calibration line incorporating the whole compositional range of the glasses. The resulting calibration line is shown in Fig. 6. The $R^{2}$ value characteristic for the calibration line is 0.934 and the deviation of the calibration points is $0.4 \mathrm{wt} \%$ at $1 \mathrm{RSD}$. Indeed, most points overlap within their uncertainty with the calibration line.

$\Delta$ feldspathic glass serie $(\mathrm{NBO} / \mathrm{T}=0)$

$\nabla$ phonolitic glass serie $(\mathrm{NBO} / \mathrm{T}=0.18)$

- andesitic glass serie $(0.16<\mathrm{NBO} / \mathrm{T}<0.32)$

- basaltic-andesitic, andesitic serie $(0.15<\mathrm{NBO} / \mathrm{T}<0.64)$

○ basaltic glass serie $(0.78<\mathrm{NBO} / \mathrm{T}<0.87)$

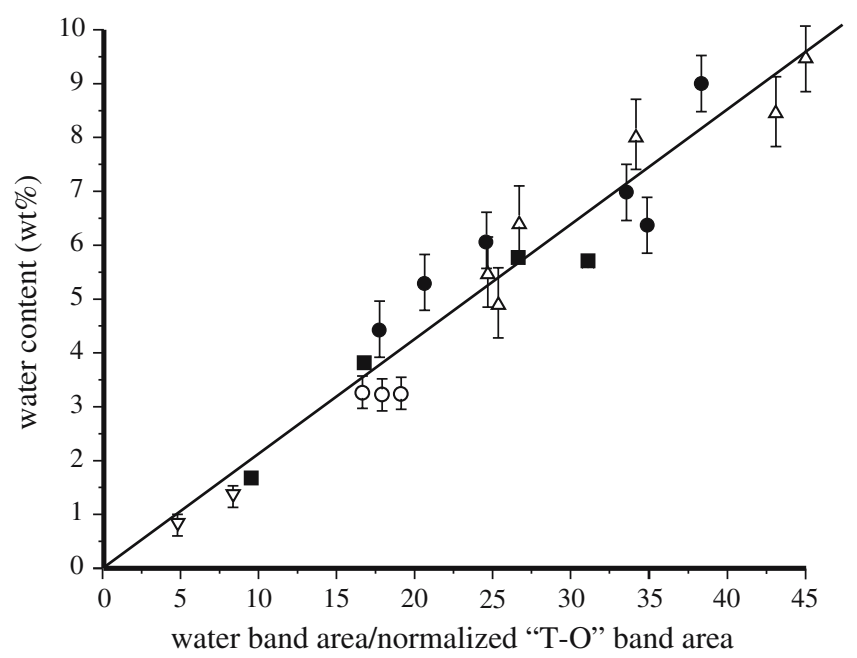

Fig. 6 Calibration line after correction for the glass composition using eq. $1 . R^{2}=0.934, \mathrm{RSD}=0.402 \mathrm{wt} \%$. The error bars for the andesitic glass series are inside the symbols
In some experiments, and particularly in natural samples, it is difficult to estimate $\operatorname{logfO}_{2}$ and $\mathrm{Fe}(\mathrm{III}) /$ $\mathrm{Fe}(\mathrm{II})$ ratio accurately, which introduces an uncertainty in the determination of the water content. However, the contribution of the $\mathrm{Fe}^{3+}$ to the total number of tetrahedral cations is minor compared to $\mathrm{Si}^{4+}$ and $\mathrm{Al}^{3+}$. Consequently, errors on the $\mathrm{Fe}^{3+}$ content do not significantly affect the accuracy of the method.

No definite detection limit for the technique has been established. However, glasses have been successfully analyzed with as little as $0.8 \mathrm{wt} \% \mathrm{H}_{2} \mathrm{O}$ and it is believed that the technique should yield meaningful results at least down to $0.8 \mathrm{wt} \%$.

\section{Comparison with previous studies}

Contrary to previous studies which were based on rhyolitic glasses only (Thomas 2000; Chabiron et al. 2004), we used the $\mathrm{T}-\mathrm{O}$ band located between 850 and $1250 \mathrm{~cm}^{-1}$ for normalization. The reasons are twofold: (1) it was not possible to work out a routine for a consistent baseline removal for the $\mathrm{T}-\mathrm{O}-\mathrm{T}$ band centered at $480 \mathrm{~cm}^{-1}$ and (2) the area of this band appears to be strongly influenced by the glass composition (Fig. 4), and this effect is rather difficult to quantify based on chemical or other peak parameters. In case of basaltic and basaltic-andesite glasses this band essentially disappears, and the subordinate peak at $565 \mathrm{~cm}^{-1}$ dominates this region of the spectra (Fig. 4).

The other important difference is that the frequencytemperature correction formula was applied on the spectra. It is possible to get systematic results without using this correction if the chemical compositions of the measured glasses are the same, since the shape and the position of the Raman bands do not change. However, there is a shift in the peak positions and variability in their shape with variable glass chemistry (Fig. 4). Thus, application of this correction is necessary for calibration over a wide compositional range.

\section{Advantages and limitations}

There are several major advantages in using Raman spectroscopy over other techniques:

1. Raman spectroscopy allows a high spatial resolution down to $5 \mu \mathrm{m}$, much below the spatial resolution of SIMS or FTIR, allowing the measurement of water contents in tiny melt inclusions and multiple analyses of large inclusions.

2. Exposure of melt inclusions to the section surface is not necessary, thereby reducing the sample preparation time and permitting the measurement of several inclusions from the same assemblage or same crystal. This is important to generate a statistically relevant set of data.

3. Short acquisition times (a 6-min measurement is sufficient for most water-bearing inclusions).

4. Broad availability and low cost. 
The application is mainly restricted by the fluorescence of some samples, which can increase the uncertainty on the baseline removal and reduce the accuracy and reproducibility of the method. Some uncertainty might also result from the deconvolution and the possible errors on the estimation of the compositional effects on the $850-1,250 \mathrm{~cm}^{-1}$ band area.

\section{Melt inclusion measurements}

As a preliminary test for the applicability of the method on silicate melt inclusions, water contents determined by both confocal Raman spectroscopy and SIMS were compared in two sets of quartz-hosted melt inclusions (Fig. 7). The first set of inclusions was trapped by quartz crystals in a granitic xenolith from Ascension Island (Webster and Rebbert 2001). The major element composition of these inclusions is rhyolitic ( $\left.68 \mathrm{wt} \% \mathrm{SiO}_{2}\right)$, with high $\mathrm{FeO}$ (up to $4 \mathrm{wt} \%$ ) and low $\mathrm{Al}_{2} \mathrm{O}_{3} \quad(\sim 10 \mathrm{wt} \%)$ (Webster and Rebbert, 2001). The second set of melt inclusions comes from large quartz crystals from a Quaternary rhyolitic ignimbrite (the $\sim 160$ ky Kos Plateau Tuff; (Smith et al. 1996; Allen 2001). These inclusions are generally glassy and homogeneous, and have a typical rhyolitic composition, with $\sim 72 \mathrm{wt} \% \mathrm{SiO}_{2}$ (Olivier Bachmann, personal communication).

In the case of the Kos Plateau Tuff melt inclusions, Raman-spectroscopic measurements were done before SIMS analyses. Since Raman analyses are nondestructive, water contents were determined from the exact same spot. In contrast, SIMS analyses were done first in the case of the Ascension Island samples, precluding Raman analyses in some of the smallest

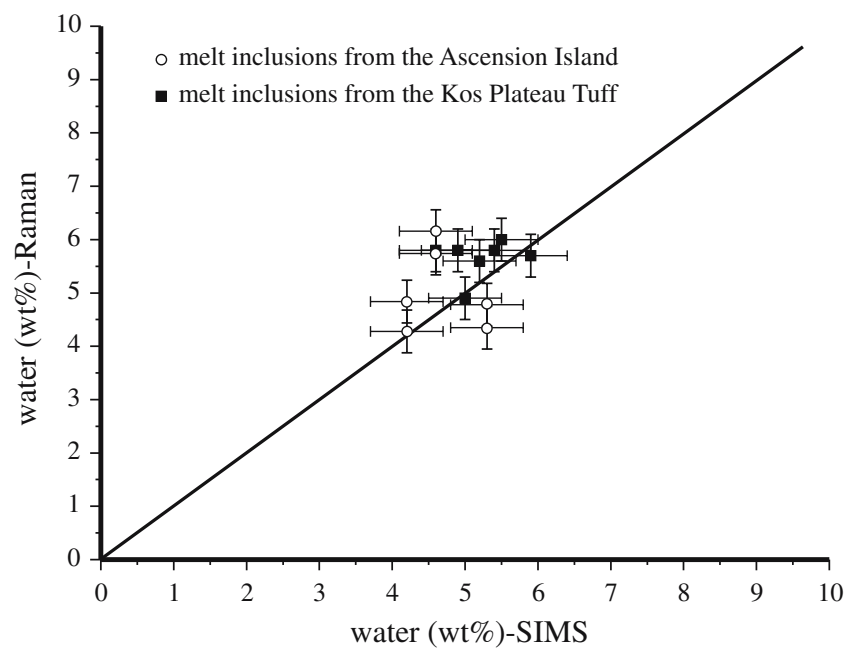

Fig. 7 Comparison of the measured water contents in silicate melt inclusions by SIMS and Raman spectroscopy. Uncertainties are given at one relative standard deviation $( \pm 0.5 \mathrm{wt} \%$ for SIMS, $\pm 0.4 \mathrm{wt} \%$ for Raman)
Table 2 Comparison of the SIMS and Raman-spectroscopy data produced on silicate melt inclusions

\begin{tabular}{|c|c|c|c|}
\hline & SIMS & Raman & $\begin{array}{l}\text { fluorescent } \\
\text { background }\end{array}$ \\
\hline \multicolumn{4}{|c|}{ Ascension Island (Webster and Rebbert 2001) } \\
\hline aig-c1 & 4.2 & 4.3 & Low \\
\hline aig-c2 & 4.6 & 5.7 & Low \\
\hline aib-b1 & 4.6 & 6.2 & High \\
\hline aib-b2 & 4.2 & 4.8 & High \\
\hline aig-a2 & 5.3 & 4.8 & High \\
\hline aig-a3 & 5.3 & 4.3 & High \\
\hline \multicolumn{4}{|c|}{ Kos-Plateau Tuff } \\
\hline kp2-4a & 5.5 & 6.0 & Low \\
\hline $\mathrm{kp} 2-4 \mathrm{~b}$ & 4.9 & 5.8 & High \\
\hline $\mathrm{kp} 5-3 \mathrm{a}$ & 5.9 & 5.7 & Low \\
\hline kp9-2a & 5.0 & 4.9 & High \\
\hline kp9-3a & 4.6 & 5.8 & High \\
\hline kpt21-4MI1 & 5.2 & 5.6 & Low \\
\hline kpt21-4MI2 & 5.4 & 5.8 & Low \\
\hline
\end{tabular}

melt inclusions (due to the damaged area in and around the SIMS crater). Therefore, in most cases, different melt inclusions had to be analyzed from the same crystal, despite the fact that SIMS measurements indicate some variability in water content in nearby melt inclusions.

As shown in Fig.7 and Table 2, the water concentrations determined by both methods are in good agreement; most of the data points fall, within error, on a 1:1 line. Only a couple of inclusions from the Kos Plateau Tuff series, which show fairly high baselines in their Raman spectra (Table 2), yield slightly lower water content by SIMS than by Raman. This discrepancy could be due to the fact that the inclusions were not reheated prior to Raman analysis. The general experience shows that reheating melt inclusions prior to Raman analysis gives more accurate data, perhaps because of the dissolution of crypto-crystalline phases in the glass, which are thought to increase the baseline on Raman spectra (Andrea Di Muro, personal communication).

\section{Notes on water speciation determination}

Chabiron et al. (2004) suggested that through deconvolution of the water band it is possible to reproduce the water speciation established by FTIR studies. We tried to reproduce these results in the rhyolitic glasses and also to extend the applicability of the method to the determination of the water speciation in andesitic and basaltic systems, but there were two serious difficulties: (1) The glass composition affects the position of the Raman bands, and the initial position of the Gaussian components strongly influences the results of the deconvolution. Using four Gaussian peaks, as suggested by Chabiron et al. (2004), a slight shift in the Gaussian peak positions or a slight change in 


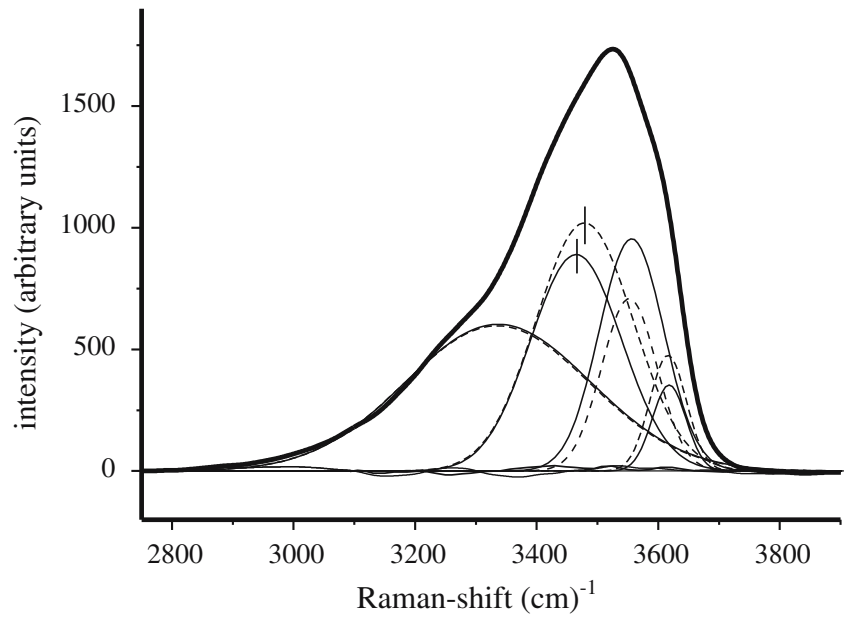

Fig. 8 Demonstration of the sensitivity of the water band deconvolution. Two deconvolutions are shown and both yield the same quality fit $\left(R^{2}=0.99975\right)$. However, shifting the Gaussiancomponent centered at $3,478 \mathrm{~cm}^{-1}$ to $3,465 \mathrm{~cm}^{-1}$ significantly affects the peak area ratio. The calculated ratio between $\mathrm{OH} / \mathrm{H}_{2} \mathrm{O}$ species is increased by $30 \mathrm{rel} \%$. Thus, without a tightly constrained peak position, even a very small error in baseline removal can result in significantly different results in the deconvolution

other peak parameters significantly modified the peak ratios without affecting the quality of the fit (Fig. 8) (2) small uncertainties on the baseline removal also resulted in significant differences in the Gaussian peak area ratios, although the total band area is only slightly affected.

To reduce the uncertainties of the deconvolution and study the dependence of the water band shape on the total water content and the matrix glass composition, the first and second derivatives of the water band signal were determined first. This allowed us to find the exact positions of characteristic points of the water signal and to identify the positions of the band maximum, all inflection points and all the shoulders. The peak maximum is at the position where the first derivative is equal to zero, the inflection points are located where the second derivative is equal to zero, and the shoulders are identified by local intermediate maxima on the second derivative.

In Fig. 9 the water bands of an alkalifeldspathic, an andesitic and a basaltic glass with identical $(5.5 \pm 0.3 \mathrm{wt} \%)$ total water content were compared. The figure shows that the glass matrix composition has a very significant effect on the water band shape. For example, with increasing $\mathrm{NBO} / \mathrm{T}$ the shoulder of the water peak at the high wavenumber side disappears, although it is consistently present in feldspathic glasses. The maximum of the water band and the height of the main shoulder at low wavenumbers are also significantly shifted by changes in the matrix composition (Fig. 9). The variability in shape could be the result of a change in the relative intensities of the Gaussian components, but FTIR speciation data on basaltic and andesitic glasses were not reproducible with fixed peak positions.
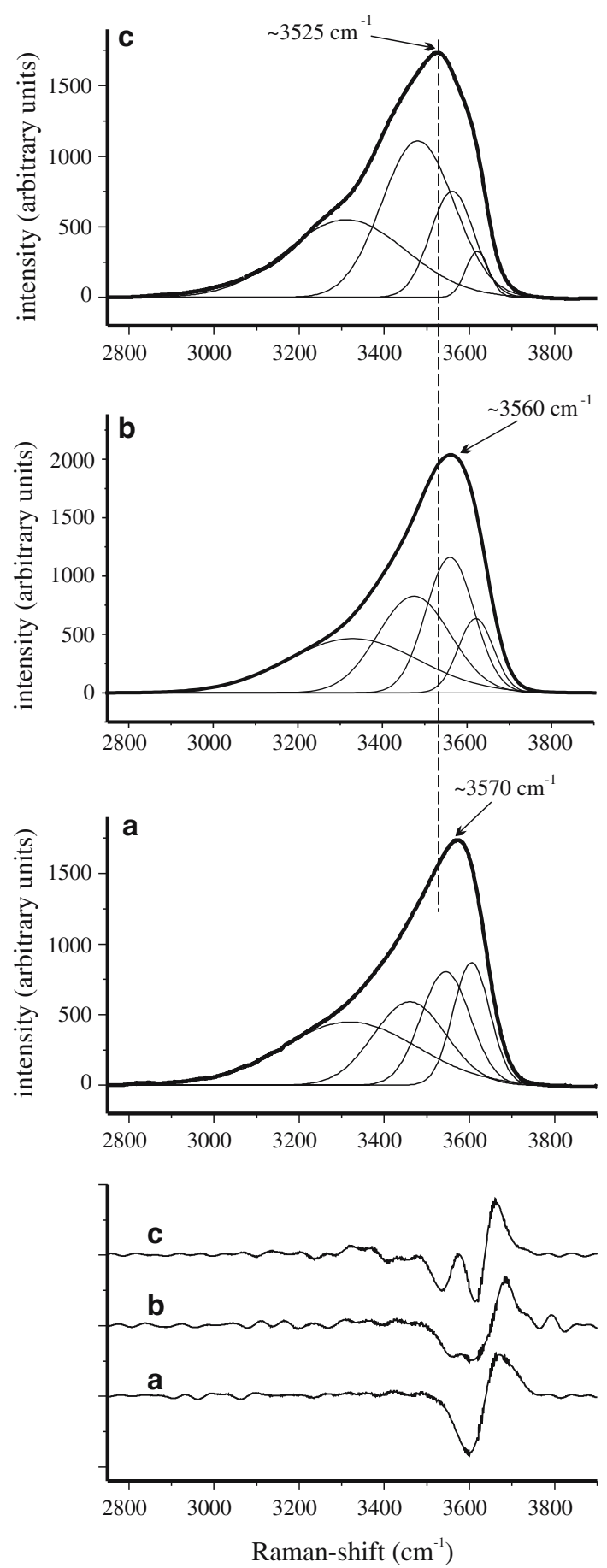

Fig. 9 Effect of the chemical composition of the glass on the water band shape. Second derivative curves of the Raman spectra of glasses having identical water content $(5.5 \pm 0.3 \mathrm{wt} \%)$ but different chemical compositions are shown a basaltic glass (B714) b andesitic glass (Run10); c rhyolitic glass [xii415]). The original water bands are also shown with the resulting optimal deconvolution. The most apparent changes induced by increasing $\mathrm{NBO} / \mathrm{T}$ are the shift of the band maxima and the disappearance of the shoulder on the high wavenumber side of the band

Because of these difficulties, a lot of work still remains to be done to develop an accurate method to measure water speciation by Raman spectroscopy in glasses with a wide compositional range. 


\section{Conclusions}

With the new approach presented in this paper, Raman spectroscopy becomes a widely applicable tool to quantify the water content of silicate glasses and melt inclusions. The unique advantages of this technique are that it is broadly available, cost- and time-efficient, and has a high spatial resolution allowing multiple analyses of the same melt inclusion. Moreover, the confocal system permits application of the approach to melt inclusions below the sample surface. This significantly increases the number of measurements from a single crystal and improves the statistical representivity of the dataset. The uncertainty of the method is within the range required for most petrogenetic applications. Achieving this result required the development of a consistent analytical procedure with special emphasis on a systematic spectral treatment. The internal standardization approach chosen in this study has the advantage of making the calibration line instrument-independent provided that the detailed analytical procedure is followed.

The water content of silicate melts has a major influence on the physical properties of magmas and controls dynamic processes, such as volcanic eruptions and the formation of ore deposits. Because of this, the calibration proposed in this study is a valuable tool to generate new data on the water content of silicate melts and will allow major progress in the investigation of magmatic processes.

Acknowledgements This research was supported by the Swiss National Science Foundation (SNF). The project number is PP00268687.

\section{References}

Allen SR (2001) Reconstruction of a major caldera-forming eruption from pyroclastic deposit characteristics: Kos Plateau Tuff, eastern Aegean Sea. J Volcanol Geoth Res 105:141-162

Chabiron A, Pironon J, Massare D (2004) Characterization of water in synthetic rhyolitic glasses and natural melt inclusions by Raman spectroscopy. Contrib Mineral Petr 146(4):485-492

Devine JD, Gardner JE, Brack HP, Layne GD, Rutherford MJ (1995) Comparison of microanalytical methods for estimating $\mathrm{H}_{2} \mathrm{O}$ contents of silicic volcanic glasses. Am Mineral 80(34):319-328

Gaetani GA, Grove TL (1998) The influence of water on melting of mantle peridotite. Contrib Mineral Petr 131(4):323-346

Hauri E, Wang JH, Dixon JE, King PL, Mandeville C, Newman S (2002) SIMS analysis of volatiles in silicate glasses 1. Calibration, matrix effects and comparisons with FTIR. Chem Geol 183(1-4):99-114

Hervig RL, Dunbar NW (1992) Cause of chemical zoning in the Bishop (California) and Bandelier (New Mexico) magma chambers. Earth Planet Sc Lett 111:97-108

Ihinger PD, Hervig RL, McMillan PF (1994a) Analytical methods for volatiles in glasses. In: Volatiles in Magmas, vol 30. pp 67121
Ihinger PD, Hervig RL, McMillan PM (1994b) Analytical methods for volatiles in glasses. In: Carroll M, Holloway JR (eds) Volatiles in Magmas, vol 30. Reviews in Mineralogy, Mineralogical Society of America, pp 67-121

Keresztury G (2002) Raman-spectroscopy: theory. In: Chalmers JMG, P.R. (ed) Handbook of Vibrational Spectroscopy, vol 1. pp 71-87

Kagi R, Muntener O, Ulmer P, Ottolini L (2005) Piston-cylinder experiments on $\mathrm{H}_{2} \mathrm{O}$ undersaturated $\mathrm{Fe}$-bearing systems: An experimental setup approaching $\mathrm{f}\left(\mathrm{O}_{2}\right)$ conditions of natural calc-alkaline magmas. Am Miner 90(4):708-717

King PL, Vennemann TW, Holloway JR, Hervig RL, Lowenstern JB, Forneris JF (2002) Analytical techniques for volatiles: A case study using intermediate (andesitic) glasses. Am Mineral 87(8-9): 1077-1089

Kress VC, Carmichael ISE (1991) The compressibility of silicate liquids containing $\mathrm{Fe}_{2} \mathrm{O}_{3}$ and the effect of composition, temperature, oxygen fugacity and pressure on their redox states. Contrib Mineral Petrol 108(1-2):82-92

Long DA (2002) The Raman Effect: a unified treatment of the theory of Raman scattering by molecules. John Wiley \& Sons Ltd, Chichester

Lowenstern JB (1995) Applications of silicate melt inclusions to the study of magmatic volatiles. In: Thompson JFH (ed) Magmas, Fluids, and Ore Deposits, vol Short Course Volume 23. Minerological Association of Canada, Victoria, pp 71-101

Mandeville CW, Webster JD, Rutherford MJ, Taylor BE, Timbal A, Faure K (2002) Determination of molar absorptivities for infrared absorption bands of $\mathrm{H} 2 \mathrm{O}$ in andesitic glasses. Am Miner 87(7):813-821

Matson DW, Sharma SK, Philpotts JA (1983) The structure of high-silica alkali-silicate glasses - a Raman-spectroscopic investigation. J Non-Cryst Solids 58(2-3):323-352

McMillan P, Piriou B, Navrotsky A (1982) A Raman-spectroscopic study of glasses along the joins silica-calcium aluminate, silicasodium aluminate, and silica-potassium aluminate. Geochim Cosmochim Acta 46(11):2021-2037

McMillan PF, Wolf GH (1995) Vibrational spectroscopy of silicate liquids. In: Structure, Dynamics and Properties of Silicate Melts, vol 32. pp 247-315

McMillan PF, Wolf GH, Poe BT (1992) Vibrational spectroscopy of silicate liquids and glasses. Chem Geol 96(3-4):351-366

Morgan GB, London D (1996) Optimizing the electron microprobe analysis of hydrous alkali aluminosilicate glasses. Am Mineral 81(9-10):1176-1185

Morizet Y, Brooker RA, Kohn SC (2002) $\mathrm{CO}_{2}$ in haplo-phonolite Melt: Solubility, speciation and carbonate complexation. Geochim Cosmochim Acta 66(10):1809-1820

Muntener O, Kelemen PB, Grove TL (2001) The role of $\mathrm{H} 2 \mathrm{O}$ during crystallization of primitive arc magmas under uppermost mantle conditions and genesis of igneous pyroxenites: an experimental study. Contrib Mineral Petrol 141(6):643-658

Mysen B (1997) Aluminosilicate melts: Structure, composition and temperature. Contrib Mineral Petrol 127(1-2):104-118

Mysen BO (1999) Structure and properties of magmatic liquids: From haplobasalt to haploandesite. Geochim Cosmochim Acta 63(1):95-112

Nash WP (1992) Analysis of oxygen with the electron microprobe: Applications to hydrated glass and minerals. Am Mineral $77: 453-457$

Sharma SK, Cooney TF, Wang ZF, vanderLaan S (1997) Raman band assignments of silicate and germanate glasses using highpressure and high-temperature spectral data. J Raman Spectrosc 28(9):697-709

Smith PE, York D, Chen Y, Evensen NM (1996) Single crystal ${ }^{40} \mathrm{Ar} /{ }^{39} \mathrm{Ar}$ dating of a late Quaternary paroxysm on Kos, Greece; concordance of terrestrial and marine ages. Geophys Res Lett 23(21):3047-3050

Thomas R (2000) Determination of water contents of granite melt inclusions by confocal laser Raman microprobe spectroscopy. Am Mineral 85(5-6):868-872 
Wang ZF, Cooney TF, Sharma SK (1993) High-temperature structural investigation of $\mathrm{Na}_{2} \mathrm{O} \cdot 0.5 \mathrm{Fe}_{2} \mathrm{O}_{3} .3 \mathrm{SiO}_{2}$ and $\mathrm{Na}_{2} \mathrm{O}$.$\mathrm{FeO} .3 \mathrm{SiO}_{2}$ melts and glasses. Contrib Mineral Petrol 115(1):112-122

Wang ZF, Cooney TF, Sharma SK (1995) In-situ structural investigation of iron-containing silicate liquids and glasses. Geochim Cosmochim Acta 59(8):1571-1577
Webster JD, Rebbert CR (2001) The geochemical signature of fluid-saturated magma determined from silicate melt inclusions in Ascension Island granite xenoliths. Geochim Cosmochim Acta 65:123-136

Westrich HR (1987) Determination of water in volcanic glasses by Karl Fischer titration. Chem Geol 63:335-340 